\title{
Clinical significance of subclinical carotid atherosclerosis and its relationship with echocardiographic parameters in non-diabetic chronic kidney disease patients
}

\author{
Jwa-Kyung Kim, Young Rim Song, Min Gang Kim, Hyung Jik Kim and Sung Gyun Kim
}

\begin{abstract}
Background: Non-diabetic chronic kidney disease (CKD) patients are a heterogeneous group with a variety of prognosis. We investigated the role of subclinical carotid atherosclerosis for the prediction of adverse cardiovascular (CV) outcomes in these patients, and tried to identify clinical and echocardiographic parameters associated with subclinical carotid atherosclerosis.

Methods: As a prospective design, 182 asymptomatic non-diabetic CKD patients underwent carotid ultrasonography and Doppler echocardiography. Carotid atherosclerosis was defined as a carotid intima-media thickness $\geq 1.0 \mathrm{~mm}$ and/or the presence of plaque.

Results: During the mean follow-up period of $28.8 \pm 16.1$ months, 23 adverse CV events occurred. Patients with carotid atherosclerosis $(99,54.4 \%)$ showed significantly higher rates of annual CV events than those without (8.6 vs. 1.5\%, $\mathrm{p}<0.001)$. Particularly, the presence of carotid plaque was a powerful predictor of adverse CV outcomes (OR 7.80, 95\% Cl 1.45-45.97). Clinical parameters associated with the presence of subclinical carotid atherosclerosis were old age, previous history of hypertension, increased pulse pressure, and higher high-sensitivity C-reactive protein (hs-CRP) level. By echocardiography, early diastolic mitral annular velocity ( $\left.E^{\prime}\right)$ and the ratio of early peak transmitral inflow velocity (E) to $E^{\prime}\left(E / E^{\prime}\right)$ were closely related with the presence of carotid atherosclerosis. A multivariate analysis showed that age, hs-CRP, and E/E' were significant determinants of carotid atherosclerosis.
\end{abstract}

Conclusions: Carotid plaque, even subclinical, was closely associated with a poor prognosis in non-diabetic CKD patients. Increased age, hs-CRP level, and E/E' ratio may be useful markers suggesting the presence of carotid atherosclerosis in these patients.

Keywords: Carotid atherosclerosis, Cardiovascular events, Non-diabetic chronic kidney disease, Increased left ventricular filling pressure

\section{Background}

Patients with chronic kidney disease (CKD) are often regarded as the highest risk population for cardiovascular (CV) disease. However, CKD patients are a heterogeneous group, and there are subgroups at lower risk for $\mathrm{CV}$ complications as well as subgroups with increased need of intensive medical care and close follow-up. Since

\footnotetext{
* Correspondence: imnksk@gmail.com

Department of Internal Medicine \& Kidney Research Institute, Hallym University College of Medicine, 896, Pyeongchon-dong, Dongan-gu, Anyang-si 431-070, Korea
}

(c) 2013 Kim et al.; licensee BioMed Central Ltd. This is an open access article distributed under the terms of the Creative Commons Attribution License (http://creativecommons.org/licenses/by/2.0), which permits unrestricted use, distribution, and reproduction in any medium, provided the original work is properly cited. equivalent, patients with diabetic CKD usually have increased $\mathrm{CV}$ risk and poor prognosis, as compared to those with non-diabetic CKD. However, the long-term prognoses of non-diabetic CKD patients are especially diverse; therefore, non-invasive and effective risk assessments are particularly needed for this group. Atherosclerosis is the main pathophysiological link between CKD and CV disease, and the presence of carotid atherosclerosis, even subclinical, could be a useful maker predicting adverse CV outcomes [1-4]. To date, current 
guidelines recommend the use of carotid atherosclerosis in asymptomatic patients at intermediate risk. Therefore, screening for carotid atherosclerosis may be helpful for the identification of high-risk group in non-diabetic CKD patients, although routine screening for carotid atherosclerosis in all CKD patients (including diabetes) cannot be justified.

According to the previous multi-ethnic observational study, subclinical carotid atherosclerosis was closely associated with significant alterations in myocardial strain parameters, reflecting incipient myocardial systolic and diastolic dysfunction [5]. However, no data regarding the relationship between echocardiographic parameters and carotid atherosclerosis have been reported in these patients.

In this study, we examined the impact of subclinical carotid atherosclerosis, as measured by carotid intimamedia thickness (cIMT) and carotid plaque, on longterm CV outcomes in asymptomatic non-diabetic CKD patients, and tried to identify clinical and echocardiographic parameters suggesting the presence of subclinical carotid atherosclerosis in these patients.

\section{Methods}

\section{Population}

Since January 2008, our hospital began a CV surveillance program for asymptomatic stable CKD patients. CKD is defined as low estimated glomerular filtration rate $($ eGFR) $<60 \mathrm{~mL} / \mathrm{min} / 1.73 \mathrm{~m} 2$ with abnormalities of kidney structure or function, present for $>3$ months with implications for health. To avoid the enrollment of ineligible patients, those taking any medications that may affect renal function, such as non-steroidal anti-inflammatory drugs, antibiotics, and herbal medications at the time of evaluation were not included. Demographic, laboratory, and clinical data including classic $\mathrm{CV}$ risk factors were obtained. Additionally, resting ECG, Doppler echocardiography (Vivid 7; GE Medical, Horton, Norway), and carotid B-mode ultrasonography (US) (Vivid 7; GE Medical, Horton, Norway) were performed with patient consent. Two hundred and thirty-four patients were registered in our cohort between January 2008 and December 2012. Fifty-two patients were excluded for the following reasons: incomplete data from echocardiography or carotid US $(n=11)$, previously diagnosed atherosclerotic diseases such as cerebrovascular accidents $(n=7)$, coronary artery disease $(n=13)$, peripheral arterial disease $(n=2)$, presence of edema at the time of echocardiography $(n=12)$, or previously diagnosed cardiomyopathy $(n=7)$. Consequently, data from 182 patients were analyzed, and informed consent was obtained from each patient. This study was approved by the Hallym University Sacred heart hospital Institutional Review Board/Ethics committee and conducted according to the Declaration of Helsinki.

\section{Diagnostic work-up}

All echocardiographic images were obtained with standard techniques using the M-mode, 2D, and Doppler measurements in accordance with the American Society of Echocardiography guidelines. LV systolic function was assessed by LV ejection fraction (LVEF) using the modified biplane Simpson's method with apical two- and four-chamber views. The LV mass was calculated according to the recommended ASE formula and indexed for body surface area (BSA) (LVMI, g/m2). LV diastolic filling pattern was assessed by the transmitral inflow velocity curve, including peak $\mathrm{E}$ velocity (peak transmitral velocity during early diastole), deceleration time (DT), peak A velocity (peak transmitral atrial filling velocity during late diastole), and E/A ratio. For tissue Doppler images, $2.0-\mathrm{mm}$ sample volume was sequentially placed at septal and lateral annular sites and the average of the two values was used to evaluate the early (E') and late (A') diastolic mitral annular velocities. Filters and gains were adjusted to minimize background noise and maximize tissue signal, and the E/E' ratio was also obtained. The left atrial (LA) volume was also measured from the apical two- and four-chamber views at endsystole by tracing the LA borders using planimetry. The LA volume index (LAVI) was calculated by dividing the LA volume by BSA.

Ultrasonographical B-mode imaging of bilateral carotid arteries was also performed with high resolution real-time US with a $12-\mathrm{MHz}$ linear-assay transducer. Bilateral carotid arteries, carotid bulbs, and internal carotid arteries were examined by two different longitudinal projections, and $2 \mathrm{D}$ images were acquired on the $\mathrm{R}$ wave of the electrocardiography (ECG), frozen in end-diastole and analyzed off-line. The cIMT was defined as the distance between the leading edges of the lumen interface and the mediaadventitia interface at the far wall in plaque-free arterial segments. Carotid plaque was defined as a focal structure encroaching into the arterial lumen of at least $0.5 \mathrm{~mm}$ or $50 \%$ of the surrounding IMT value, or demonstrates a thickness $>1.5 \mathrm{~mm}$ as measured from the media-adventitia interface to the intima-lumen interface [6]. Carotid atherosclerosis was defined as carotid intima-media thickness $(\mathrm{cIMT}) \geq 1.0 \mathrm{~mm}$ and/or the presence of plaque.

\section{Follow-up and endpoints}

Patients were followed by periodic examination in an outpatient setting. For patients not followed at our center, information was obtained by a telephone interview. The end of follow-up was determined by the occurrence of adverse $\mathrm{CV}$ events or by the date of last patient contact in the hospital for those without events. CV events were defined as fatal or non-fatal acute coronary syndrome (ACS) (e.g., acute myocardial infarction and unstable angina), or cerebrovascular events. ACS was defined using 
the standard criteria of history, ECG, and cardiac enzyme levels. In cases of multiple cardiac events, only the first event was used as the end point of follow-up.

\section{Statistical analysis}

Statistical analyses were performed using SPSS version 18.0 (SPSS Inc., Chicago, IL, USA). All variables were expressed as means \pm standard deviations (SDs) or medians with ranges unless otherwise indicated. The KolmogorovSmirnov test was used to analyze the normality of distributions, and natural log values were used for skewed data. Correlations between clinical or echocardiographic factors and carotid atherosclerosis were evaluated using Spearman's rank correlation. By multiple regression analysis, the effects of clinical and echocardiographic parameters on the presence of carotid atherosclerosis were evaluated and an area under the receiver operating characteristic (ROC) curve was used to compare various echocardiographic parameters for predicting carotid atherosclerosis. Survival curves were derived by the Kaplan-Meier method; the differences between survival curves were compared using the log-rank test. The multivariate Cox proportional hazard model was used to evaluate independent predictors of adverse CV outcomes. A $\mathrm{p}$-value $<0.05$ was considered statistically significant.

\section{Results}

A total of 182 patients (mean age, $67.8 \pm 14.7$ years; males, 96 [52.7\%]) were analyzed. Subclinical carotid atherosclerosis was found in 99 patients $(54.4 \%)$; the demographic and biochemical characteristics of the patients with and without carotid atherosclerosis are compared in Table 1. The mean cIMT value of the patients with carotid atherosclerosis was $0.95 \pm 0.18 \mathrm{~mm}$, and $90.9 \%$ of them had carotid plaque. The group with carotid atherosclerosis was significantly older and had a higher prevalence of hypertension and increased pulse pressure. In addition, serum phosphorus level was significantly lower and low-density lipoprotein (LDL) cholesterol, triglyceride, and high-sensitivity C-reactive protein (hs-CRP) levels were higher in these patients. However, there were no differences in the amount of proteinuria or the prevalence of statin use between the two groups.

\section{Carotid atherosclerosis and its relationship with echocardiographic parameters}

Differences in various echocardiographic parameters according to the presence of carotid atherosclerosis are shown in Table 2. The prevalence of LV hypertrophy was higher in patients with carotid atherosclerosis (43.4 vs. $31.3 \%, p=0.043)$; however, the LV systolic and diastolic volume indices, LVEF, LVMI and LAVI were similar between the two groups. Interestingly, pronounced differences were found in markers of elevated LV filling pressure between the two groups; the E/A ratio $(0.72 \pm$ 0.22 vs. $0.83 \pm 0.32, p=0.032$ ) was significantly lower while the DT $(239.2 \pm 46.4$ vs. $219.3 \pm 46.4, p=0.019)$ was longer in patients with carotid atherosclerosis than in patients without. Furthermore, tissue Doppler echocardiography showed similar findings: E' $(5.6 \pm 2.2 v s$. $6.6 \pm 1.9, p=0.003)$ was lower, but the E/E' ratio (12.5 \pm 4.4 vs. $10.2 \pm 3.1, p<0.001)$ was higher in patients with carotid atherosclerosis (Table 2).

According to the results of correlation analysis, carotid atherosclerosis had a strong positive association with age $(r=0.486, p<0.001)$, history of hypertension $(r=0.228$, $p=0.002)$, pulse pressure $(r=0.238, p=0.001)$, and hsCRP level $(r=0.436, p<0.001)$. For the echocardiographic parameters, carotid atherosclerosis was closely associated with the E/A ratio $(r=-0.168, p=0.035)$, E' $(r=-0.245, p=0.001), \mathrm{A}^{\prime}(r=-0.209, p=0.009)$ and E/E' ratio $(r=0.339, p<0.001)$. Using these results, a stepwise multiple regression analysis showed that age $(\beta=0.02, p<0.001)$, hs-CRP level $(\beta=0.08, p=0.013)$ and $E / E$ ' ratio $(\beta=0.02, p=0.034)$ were significant determinants of carotid atherosclerosis in non-diabetic CKD patients, even after adjustments for other wellknown $\mathrm{CV}$ risk factors (Table 3). The area under the ROC curve of age, hs-CRP and E/E' ratio to predict carotid atherosclerosis were $0.782(0.690-0.851), 0.745$ (0.661 - 0.830), and 0.726 (0.623-0.801), respectively. When age, hs-CRP and E/E' were combined, the AUC significantly increased to 0.884 (Figure 1).

\section{Risk factors for long-term CV outcomes}

During the mean follow-up period of $28.8 \pm 16.1$ months, 23 adverse CV events occurred: 20 cases with and 3 cases without carotid atherosclerosis. Fatal CV events were occurred in 3 cases at 20.3, 30.3 and 31.5 months of follow-up. The overall annual $\mathrm{CV}$ event rate per person-year of follow-up was 5.3\%, and the rate was significantly higher in patients with carotid atherosclerosis than in those without (8.6 vs. $1.5 \%$, hazard ratio $5.8, \log$ rank $p=0.004$ ) (Figure 2).

To investigate the effect of subclinical carotid atherosclerosis on the occurrence of adverse CV outcomes, we performed a Cox regression analysis. By univariate analysis, smoking, history of hypertension, LVH, increased $\mathrm{E} / \mathrm{A}, \mathrm{E} / \mathrm{E}^{\prime}$ ratios, carotid plaque, and cIMT values were all significant predictors. After adjustment for these factors, only smoking (OR 3.13, 95\% CI 1.10-9.09), an increased E/E' ratio (OR 1.10, 95\% CI 1.01-1.21), and the presence of carotid plaque (OR 7.80, 95\% CI 1.45-45.97) were significant independent predictors of $\mathrm{CV}$ events (Table 4). Considering that cIMT lost its significance in our multivariate analysis, the presence of carotid plaque is thought to be the main factor causing adverse $\mathrm{CV}$ events in patients with carotid atherosclerosis. 
Table 1 Clinical characteristics of the study population

\begin{tabular}{|c|c|c|c|c|}
\hline \multirow[t]{2}{*}{ Clinical characteristics } & \multirow[t]{2}{*}{ Total $(n=182)$} & \multicolumn{3}{|c|}{ Carotid atherosclerosis } \\
\hline & & $+(n=99,54.4 \%)$ & $-(n=83,45.6 \%)$ & $p$ \\
\hline Age (years) & $67.8 \pm 14.7$ & $74.5 \pm 9.8$ & $59.9 \pm 15.6$ & $<0.001$ \\
\hline Male, $n(\%)$ & $96(52.7)$ & $54(54.5)$ & $42(50.6)$ & 0.351 \\
\hline Smoker, n (\%) & $70(38.4)$ & $41(41.4)$ & $29(34.9)$ & 0.756 \\
\hline Body mass index $\left(\mathrm{kg} / \mathrm{m}^{2}\right)$ & $24.1 \pm 3.4$ & $23.6 \pm 3.1$ & $24.7 \pm 3.8$ & 0.065 \\
\hline Hypertension, n (\%) & $129(70.8)$ & $81(81.8)$ & $48(57.8)$ & 0.001 \\
\hline Systolic blood pressure (mmHg) & $134.3 \pm 21.0$ & $136.0 \pm 23.4$ & $131.5 \pm 17.4$ & 0.093 \\
\hline Diastolic blood pressure $(\mathrm{mmHg})$ & $75.5 \pm 12.0$ & $73.7 \pm 12.6$ & $77.6 \pm 10.8$ & 0.026 \\
\hline Pulse pressure $(\mathrm{mmHg})$ & $58.8 \pm 17.1$ & $62.9 \pm 18.9$ & $53.9 \pm 13.1$ & $<0.001$ \\
\hline \multicolumn{5}{|l|}{ Baseline laboratory findings } \\
\hline Hemoglobin (g/dL) & $11.3 \pm 2.1$ & $11.5 \pm 2.0$ & $11.3 \pm 2.2$ & 0.553 \\
\hline Albumin (g/dL) & $3.9 \pm 0.6$ & $3.8 \pm 0.6$ & $4.0 \pm 0.6$ & 0.144 \\
\hline Blood urea nitrogen $(\mathrm{mg} / \mathrm{dL})^{*}$ & $28.7(10.8-118.3)$ & $30.9(10.8-118.3)$ & $27.1(12.2-99.0)$ & 0.065 \\
\hline Creatinine (mg/dL) & $2.6 \pm 2.5$ & $2.7 \pm 2.0$ & $2.4 \pm 1.7$ & 0.229 \\
\hline eGFR (mL/min/1.73 m²) & $28.1 \pm 16.1$ & $23.6 \pm 15.5$ & $30.1 \pm 18.5$ & 0.185 \\
\hline Calcium (Ca) & $8.8 \pm 0.7$ & $8.8 \pm 0.6$ & $8.6 \pm 0.8$ & 0.128 \\
\hline Phosphorus (P) & $3.7 \pm 1.2$ & $4.0 \pm 1.4$ & $3.5 \pm 0.9$ & 0.030 \\
\hline $\mathrm{Ca} * \mathrm{P}$ product & $34.6 \pm 9.4$ & $35.4 \pm 18.3$ & $34.2 \pm 10.8$ & 0.292 \\
\hline Total cholesterol (mg/dL) & $163.1 \pm 44.8$ & $169.8 \pm 41.3$ & $157.6 \pm 47.1$ & 0.092 \\
\hline HDL-cholesterol (mg/dL) & $47.0 \pm 15.2$ & $47.9 \pm 16.5$ & $45.9 \pm 12.9$ & 0.456 \\
\hline LDL-cholesterol (mg/dL) & $99.8 \pm 35.2$ & $108.9 \pm 35.8$ & $93.2 \pm 33.3$ & 0.011 \\
\hline Triglyceride (mg/dL) & $112.9 \pm 51.7$ & $128.2 \pm 51.3$ & $101.6 \pm 49.4$ & 0.003 \\
\hline Urine PCR† & $-1.17 \pm 1.42$ & $-1.34 \pm 1.27$ & $-0.98 \pm 1.57$ & 0.103 \\
\hline $\mathrm{hs}-\mathrm{CRP}(\mathrm{mg} / \mathrm{L}) \dagger$ & $-0.20 \pm 1.12$ & $-0.01 \pm 1.19$ & $-0.43 \pm 0.98$ & $<0.001$ \\
\hline Statin use, n (\%) & $105(57.6)$ & $61(61.6)$ & $44(53.0)$ & 0.041 \\
\hline cIMT (mm) & $0.87 \pm 0.18$ & $0.95 \pm 0.18$ & $0.75 \pm 0.09$ & $<0.001$ \\
\hline Plaque, n (\%) & $90(49.5)$ & $90(90.9)$ & - & - \\
\hline
\end{tabular}

Abbreviations: HDL, High-density lipoprotein; LDL, Low-density lipoprotein; urine PCR, Urine protein-to-creatinine ratio. * , median with ranges. $\dagger$, log-transformed.

\section{Discussion}

In this study, we examined the long-term outcomes and predictors of subclinical carotid atherosclerosis among non-diabetic, pre-dialysis CKD patients. With a prevalence of $54.4 \%$, carotid atherosclerosis was an independent risk factor for adverse $\mathrm{CV}$ outcomes. In particular, carotid plaque increased the risk of $\mathrm{CV}$ events by 7.8 times. Age, hs-CRP level, and E/E' ratio could be significant determinants suggesting the presence of subclinical carotid atherosclerosis in these patients.

The number of non-diabetic CKD patients continues to grow owing to the increasing number of elderly people and the recent obesity epidemic. Although CKD itself is considered to be a powerful determinant of $\mathrm{CV}$ mortality, non-diabetic CKD patients are a heterogeneous group with a variety of prognoses. The need for effective risk stratification assumes unprecedented significance in these patients, and identification of carotid atherosclerosis, even subclinical, could be a useful tool for prediction of future prognosis.

The prevalence of subclinical carotid atherosclerosis is $<5 \%$ in healthy young, and $5-10 \%$ among the elderly people [7]. In certain populations, however, the prevalence becomes much higher: $15-25 \%$ in subjects with hypertension or PAD [8,9], and up to $70 \%$ in patients with CAD [10]. Our data showed a fairly high prevalence of subclinical carotid atherosclerosis in non-diabetic CKD patients; about half of the patients $(54.4 \%)$ had carotid atherosclerosis, and most of them had carotid plaque. Individuals with carotid atherosclerosis had significantly higher rates of adverse $\mathrm{CV}$ events compared to patients without. These findings are in keeping with those of previous studies, which demonstrated the harmful effect of carotid atherosclerosis on the risk of $\mathrm{CV}$ mortality and morbidity. However, we additionally found 
Table 2 Differences in echocardiographic parameters according to the presence of carotid atherosclerosis

\begin{tabular}{|c|c|c|c|c|}
\hline \multirow[t]{2}{*}{ Clinical characteristics } & \multirow[t]{2}{*}{ Total $(n=182)$} & \multicolumn{3}{|c|}{ Carotid atherosclerosis } \\
\hline & & $+(n=99,54.4 \%)$ & $-(n=83,45.6 \%)$ & $p$ \\
\hline LV end-diastolic diameter (mm) & $47.3 \pm 5.7$ & $46.9 \pm 6.7$ & $47.7 \pm 4.2$ & 0.392 \\
\hline LV end-systolic diameter (mm) & $31.7 \pm 5.6$ & $31.5 \pm 6.1$ & $32.1 \pm 5.2$ & 0.555 \\
\hline LV end-diastolic volume index $\left(\mathrm{mL} / \mathrm{m}^{2}\right)$ & $52.1 \pm 9.1$ & $48.9 \pm 12.8$ & $55.6 \pm 13.3$ & 0.109 \\
\hline LV end- systolic volume index $\left(\mathrm{mL} / \mathrm{m}^{2}\right)$ & $21.3 \pm 9.2$ & $20.6 \pm 9.2$ & $22.2 \pm 9.1$ & 0.373 \\
\hline LVMI $\left(g / m^{2}\right)$ & $99.3 \pm 29.5$ & $94.3 \pm 27.3$ & $101.0 \pm 31.2$ & 0.170 \\
\hline LVEF (\%) & $59.1 \pm 9.7$ & 58. $0 \pm 11.0$ & $60.4 \pm 7.7$ & 0.161 \\
\hline LAVI $\left(\mathrm{mL} / \mathrm{m}^{2}\right)$ & $42.2 \pm 17.3$ & $42.9 \pm 17.7$ & $39.5 \pm 16.9$ & 0.191 \\
\hline LVH, n (\%) & $69(37.9)$ & $43(43.4)$ & $26(31.3)$ & 0.043 \\
\hline \multicolumn{5}{|l|}{ Mitral inflow velocities (mean \pm SD) } \\
\hline $\mathrm{E}(\mathrm{cm} / \mathrm{s})$ & $64.7 \pm 19.0$ & $64.1 \pm 19.2$ & $70.3 \pm 18.9$ & 0.101 \\
\hline $\mathrm{A}(\mathrm{cm} / \mathrm{s})$ & $84.3 \pm 20.4$ & $85.5 \pm 18.6$ & $82.9 \pm 22.2$ & 0.439 \\
\hline E/A ratio & $0.77 \pm 0.28$ & $0.72 \pm 0.22$ & $0.83 \pm 0.32$ & 0.032 \\
\hline $\mathrm{DT}(\mathrm{ms})$ & $231.0 \pm 48.0$ & $239.2 \pm 46.4$ & $219.3 \pm 46.4$ & 0.019 \\
\hline \multicolumn{5}{|l|}{ Tissue Doppler parameters } \\
\hline $\mathrm{E}^{\prime}(\mathrm{cm} / \mathrm{s})$ & $6.1 \pm 2.1$ & $5.6 \pm 2.2$ & $6.6 \pm 1.9$ & 0.003 \\
\hline$A^{\prime}(\mathrm{cm} / \mathrm{s})$ & $8.9 \pm 1.9$ & $8.7 \pm 2.2$ & $9.2 \pm 1.6$ & 0.090 \\
\hline E/E' ratio & $11.5 \pm 4.1$ & $12.5 \pm 4.4$ & $10.2 \pm 3.1$ & $<0.001$ \\
\hline
\end{tabular}

Abbreviations: LVMI, LV mass index; LVEF, LV ejection fraction; LAVI, Left atrial volume index; E, Early peak transmitral inflow velocity; A, late diastolic transmitral inflow velocity; DT, Deceleration time; E', Early diastolic mitral annular velocity; A', Late diastolic mitral annular velocity.

that carotid plaque, not cIMT, was a powerful predictor of $\mathrm{CV}$ outcomes. The presence of carotid plaque was associated with a 7.8 times higher risk of $\mathrm{CV}$ events, whereas cIMT lost its significance in our multivariate analysis. These findings can be explained by the fact that the main causes of non-diabetic CKD in our population were hypertension, which is a main determinant of increasing cIMT. In fact, the value of cIMT as a marker of generalized atherosclerosis has recently been called into question since the primary predictors of increased cIMT

Table 3 Clinical and echocardiographic parameters associated with carotid atherosclerosis in non-diabetic CKD patients

\begin{tabular}{|c|c|c|c|c|}
\hline \multirow[t]{2}{*}{ Parameters } & \multicolumn{2}{|c|}{ Univariate analysis } & \multicolumn{2}{|c|}{ Multivariate analysis } \\
\hline & Unstandardized coefficient & $\mathbf{P}$ & Unstandardized coefficient & $\mathbf{P}$ \\
\hline Age & $0.02(0.01,0.02)$ & $<0.001$ & $0.02(0.01,0.02)$ & $<0.001$ \\
\hline Hypertension & $0.29(0.11,0.48)$ & 0.002 & $0.12(-0.06,0.30)$ & 0.199 \\
\hline Systolic BP (mmHg) & $0.01(-0.01,0.01)$ & 0.103 & - & - \\
\hline Diastolic BP (mmHg) & $-0.01(-0.02,-0.01)$ & 0.026 & $-0.01(-0.06,0.31)$ & 0.177 \\
\hline Pulse pressure $(\mathrm{mmHg})$ & $0.01(0.01,0.02)$ & $<0.001$ & $0.01(-0.01,0.01)$ & 0.267 \\
\hline BMI $\left(\mathrm{kg} / \mathrm{m}^{2}\right)$ & $-0.01(-0.04,0.01)$ & 0.176 & & \\
\hline Urine PCR $(g / g)^{*}$ & $-0.04(-0.10,-0.01)$ & 0.097 & - & - \\
\hline hs-CRP* & $0.09(0.02,0.15)$ & 0.010 & $0.08(0.02,0.14)$ & 0.013 \\
\hline Statins & $0.11(-1.10,1.26)$ & 0.215 & - & - \\
\hline \multicolumn{5}{|l|}{ Echocardiographic data } \\
\hline $\mathrm{LVH}$ & $0.13(-0.02,0.28)$ & 0.095 & - & - \\
\hline LVEF & $-0.01(-0.01,0.01)$ & 0.161 & - & - \\
\hline E/A ratio & $-0.28(-0.56,0.01)$ & 0.052 & - & - \\
\hline $\mathrm{E}^{\prime}$ & $-0.05(-0.08,-0.02)$ & 0.003 & - & - \\
\hline E/E' ratio & $0.04(0.02,0.06)$ & $<0.001$ & $0.02(0.01,0.04)$ & 0.034 \\
\hline
\end{tabular}

*, log-transformed. 

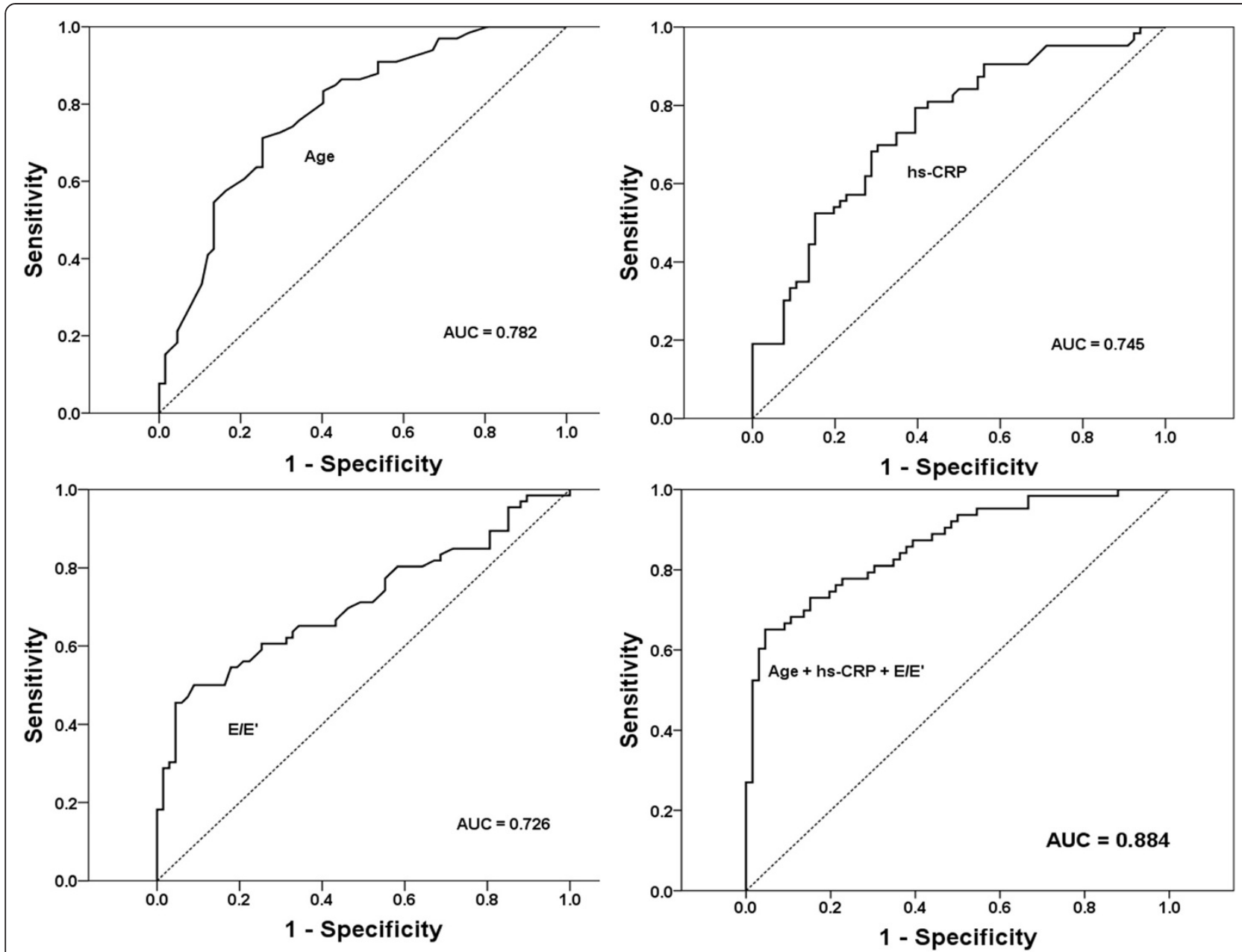

Figure 1 ROC curves for age, hs-CRP, and the E/E' ratio for the prediction of carotid atherosclerosis. When age, hs-CRP and the E/E' ratio were combined, the AUC significantly increased to 0.884 .

are age and hypertension, which do not necessarily reflect the atherosclerotic process [11,12]. Moreover, the 2007 European guidelines on hypertension have emphasized that treatment-induced regression of asymptomatic organ damage could reduce the risk of fatal and nonfatal $\mathrm{CV}$ events. This has been shown with the treatmentinduced regression of electrocardiographic LVH [13], the echocardiographic LVH [14], LVM and left atrial size [15]. However according to a recent analysis of the ELSA study, the treatment-induced cIMT changes in the carotid arteries failed to document a predictive value for CV events [16]. Therefore, the use and enthusiasm for cIMT as a marker of subclinical organ damage has considerably declined over the last years. Carotid plaque, in contrast, is regarded as a more representative marker of atherosclerotic burden, and it may have greater predictive power for CV outcomes [17].

In our study, carotid plaque, a representative marker of atherosclerosis, was a main predictor of adverse $\mathrm{CV}$ events in non-diabetic CKD patients who were not yet on dialysis treatment. This finding would support the results of SHARP (Study of Heart And Renal Protection) study which evaluated the anti-atherogenic effect of statin in large cohort of patients with pre-dialysis CKD and patients undergoing dialysis. The study showed a significant reduction in major CV events [18] with statin treatment, suggesting that atherosclerosis does play an important role for adverse CV events. However, according to the results of another two large clinical trials conducted only in patients receiving hemodialysis, 4D (Deutsche Diabetes Dialyse Studie) [19] and AURORA (A study to evaluate the Use of Rosuvastatin in subjects On Regular hemodialysis: an Assessment of survival and cardiovascular e) [20], statins showed little or no benefit as primary $\mathrm{CV}$ diseases prevention. With these, the pathophysiology of $\mathrm{CV}$ disease in non-dialysis CKD patients seems to be more strongly associated with atherosclerosis compared to that of patients receiving dialysis treatment. This may be why the carotid plaque predicted adverse CV events in our study. 

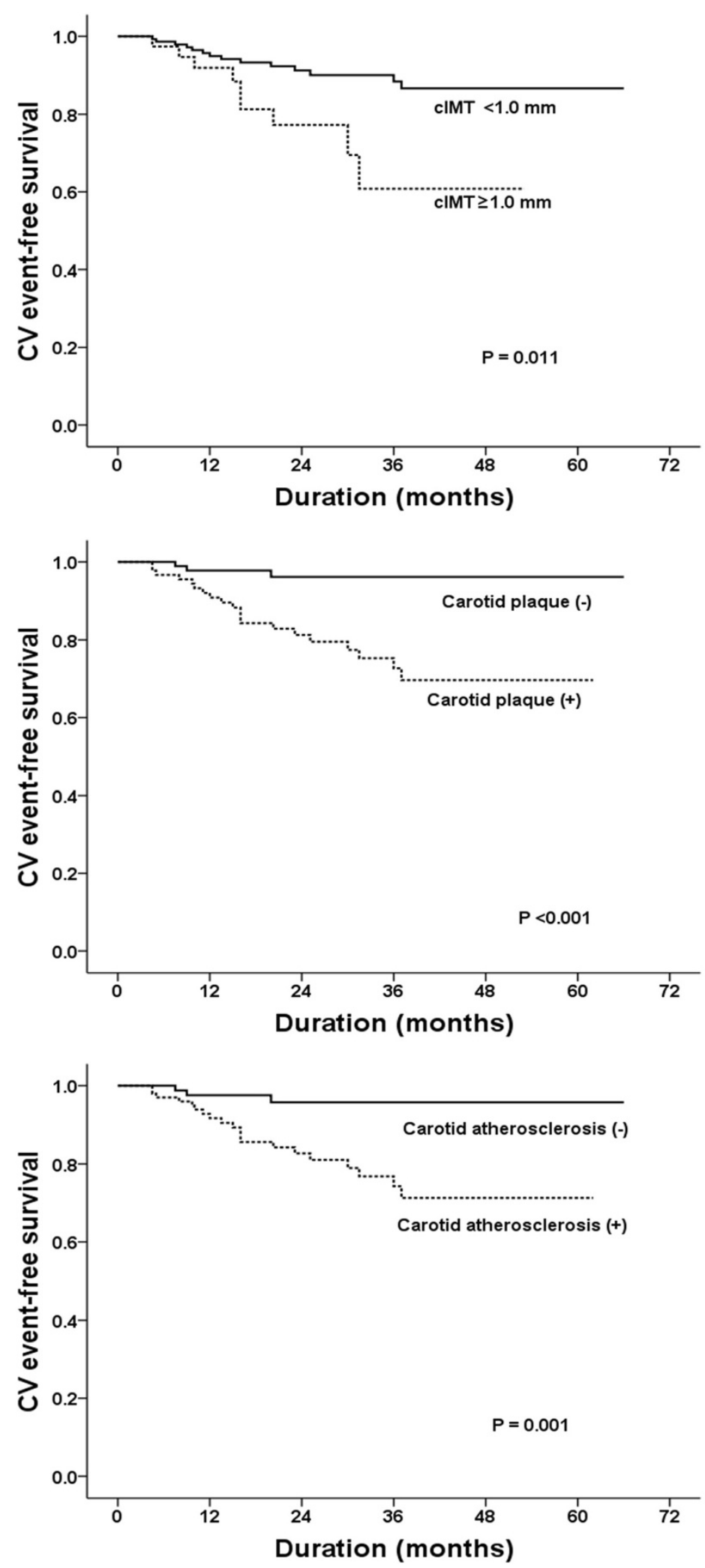

Figure 2 Cardiovascular event-free survival in analyses by cIMT, carotid plaque and carotid atherosclerosis. The presence of carotid atherosclerosis was significantly associated with poor prognosis in non-diabetic CKD patients. 
Table 4 Risk factors for adverse CV outcomes among non-diabetic CKD patients

\begin{tabular}{|c|c|c|c|c|c|}
\hline \multirow[t]{2}{*}{ Parameters } & \multicolumn{2}{|c|}{ Adverse CV events } & \multirow{2}{*}{$\begin{array}{c}\text { Univariate analysis } \\
\text { P }\end{array}$} & \multicolumn{2}{|c|}{ Multivariate analysis } \\
\hline & $+(n=23)$ & $-(n=159)$ & & $\mathrm{HR}(95 \% \mathrm{Cl})$ & $\mathbf{P}$ \\
\hline Age (years)† & $72.5 \pm 11.2$ & $67.2 \pm 15.1$ & 0.098 & $1.05(0.91-1.01)$ & 0.087 \\
\hline Male, $n(\%)$ & $13(56.5)$ & $83(52.2)$ & 0.740 & - & - \\
\hline Smokers, $n(\%) \dagger$ & $13(56.5)$ & $57(35.8)$ & 0.012 & $3.13(1.10-9.09)$ & 0.036 \\
\hline Hypertension, n (\%)† & $20(87.0)$ & $109(68.5)$ & 0.043 & $1.61(0.88-2.51)$ & 0.101 \\
\hline $\mathrm{SBP}(\mathrm{mmHg})$ & $138.9 \pm 31.0$ & $133.6 \pm 19.2$ & 0.181 & - & - \\
\hline $\mathrm{DBP}(\mathrm{mmHg})$ & $78.0 \pm 14.0$ & $75.1 \pm 11.7$ & 0.150 & - & - \\
\hline Pulse pressure $(\mathrm{mmHg})$ & $60.9 \pm 24.6$ & $58.5 \pm 15.8$ & 0.552 & - & - \\
\hline BMI $\left(\mathrm{kg} / \mathrm{m}^{2}\right)$ & $24.1 \pm 3.2$ & $24.3 \pm 3.7$ & 0.746 & & \\
\hline Serum creatinine $(\mathrm{mg} / \mathrm{dL})$ & $2.8 \pm 3.1$ & $2.7 \pm 2.4$ & 0.910 & - & - \\
\hline LDL-cholesterol (mg/dL) & $100.5 \pm 34.1$ & $96.2 \pm 41.0$ & 0.684 & - & - \\
\hline Urine $P C R^{*}$ & $-0.97 \pm 1.22$ & $-1.2 \pm 1.45$ & 0.426 & - & - \\
\hline hs-CRP (mg/L) *十 & $0.03 \pm 1.27$ & $-0.23 \pm 1.10$ & 0.220 & $1.22(0.58-1.28)$ & 0.486 \\
\hline \multicolumn{6}{|l|}{ Echocardiography } \\
\hline $\mathrm{LVH}+$ & $13(56.5)$ & $56(35.2)$ & 0.029 & $2.01(0.81-5.34)$ & 0.128 \\
\hline LVEF & $58.3 \pm 9.8$ & $59.1 \pm 9.7$ & 0.778 & - & - \\
\hline LVMI & $112.0 \pm 27.9$ & $101.4 \pm 29.5$ & 0.133 & - & - \\
\hline E/A ratiot & $0.64 \pm 0.12$ & $0.78 \pm 0.30$ & 0.013 & $0.02(0.001-0.55)$ & 0.022 \\
\hline E/E' ratiof & $13.7 \pm 5.21$ & $11.3 \pm 3.7$ & 0.003 & $1.10(1.01-1.21)$ & 0.042 \\
\hline Carotid plaque, n (\%)† & $18(78.3)$ & $72(45.3)$ & 0.001 & $7.80(1.45-45.97)$ & 0.017 \\
\hline Carotid IMT $(\mathrm{mm}) \dagger$ & $0.95 \pm 0.13$ & $0.84 \pm 0.15$ & 0.010 & $10.58(0.43-26.87)$ & 0.149 \\
\hline
\end{tabular}

t, $\mathrm{p}<0.05$ between patients with and without adverse CV events. ${ }^{*}$, log-transformed.

We then identified clinical and echocardiographic parameters suggesting the presence of subclinical carotid atherosclerosis in our patient group. According to our results, increasing age, a high hs-CRP level, and a high $\mathrm{E} / \mathrm{E}$ ' ratio were closely associated with the presence of subclinical carotid atherosclerosis. Interestingly, we found that markers of increased LV filling pressure such as the E/A ratio, DT, E' and E/E' ratio were closely associated with carotid plaque as well as cIMT. In particular, the effect of an elevated E/E' ratio on the presence of carotid atherosclerosis was independent of other $\mathrm{CV}$ risk factors, including old age, hypertension, high pulse pressure, hs-CRP level, and the use of statins. Indeed, the E/E' ratio is a representative marker of increased LV filling pressure and is usually associated with LV diastolic dysfunction, ultimately leading to LV systolic dysfunction and overt heart failure [21,22]. In fact, several longitudinal studies have revealed that the LAVI [23] and E/E' ratio $[24,25]$ can serve as independent predictors of $\mathrm{CV}$ and all-cause mortality in dialysis patients. Similarly, in our study, the E/E' ratio was an independent risk factor for both carotid atherosclerosis and poor $\mathrm{CV}$ outcomes. The close association between the E/E' ratio and carotid atherosclerosis explain why an elevated $E / E^{\prime}$ ratio is a strong and independent predictor of adverse CV outcomes in various populations.

Several pathophysiologic mechanisms can be proposed for the link between a high LV filling pressure and carotid atherosclerosis. First, high blood pressure might be one of them. The findings noted on transmitral flow and tissue Doppler findings may be reflective of more significant hypertensive heart disease; thus, the link may be hypertension causing abnormalities in the echocardiographic parameters and contributing to the development of carotid disease. Another possible explanation is vascular stiffness. As our data show, those patients with carotid atherosclerosis had a significantly higher pulse pressure than did their counterparts. In patients with end-stage renal disease, increased vascular stiffness and a resultant higher brachial-ankle pulse wave velocity was closely associated with advanced carotid atherosclerosis [26]. Increased vascular stiffness is an important aggravating factor in LV systolic and diastolic dysfunction leading to a rise in LV filling pressure [27]. Third, chronic low-grade inflammation may be related to the increase in LV filling pressure and carotid atherosclerosis. Inflammatory cytokines such as interleukin-6 (IL-6), tumor necrosis factor- $\alpha$, and hs-CRP are well-established 
markers of carotid atherosclerosis [28,29]. Such inflammatory cytokines could induce LV diastolic dysfunction or even diastolic heart failure via effects on both myocyte contractility and the extracellular matrix [30].

The current study has several limitations. First, the causal relationship between carotid atherosclerosis and increased LV filling pressure could not be precisely identified. Because both LV filling pressure and cIMT are known to arise in early-stage kidney disease, accelerated atherosclerosis could affect on the increase in LV filling pressure. A long-term follow-up study is needed to address this issue. Second, as this study was conducted at a single hospital, our results are not validated or replicated for any other data set. In addition, although we included only stable CKD patients, the possibility of acute renal deterioration during study period or the frequency of renal function measures may be one of the limitations of our study. Third, although patients with a clinically apparent volume overload status were excluded, longstanding subclinical volume overload may be present in CKD patients, and volume-overloaded hearts could have been misclassified as having increased LV filling pressure. At last, a relatively small size of population is a limitation of our study.

\section{Conclusions}

Subclinical carotid atherosclerosis is common in nondiabetic CKD patients and closely associated with adverse $\mathrm{CV}$ events. In particular, carotid plaque was an independent prognostic factor for long-term CV outcomes. Along with such well-known risk factors as old age and higher hs-CRP level, increased E/E' ratio was an important predictor suggesting the presence of carotid atherosclerosis in non-diabetic CKD patients.

\section{Abbreviations}

ACS: Acute coronary syndrome; BSA: Body surface area; CKD: Chronic kidney disease; CV: Cardiovascular; CIMT: Carotid intima-media thickness; DT: Deceleration time; eGFR: Estimated glomerular filtration rate; ECG: Electrocardiography; hs-CRP: High-sensitivity C-reactive protein; US: Ultrasonography; LVEF: LV ejection fraction; LVMI: LV mass index; LA: Left atrial; LAVI: LA volume index; E: Peak transmitral velocity during early diastole; A: Peak transmitral atrial filling velocity during late diastole; E': Early diastolic mitral annular velocity.

\section{Competing interests}

There is no conflict of interest in this study. No funding in this study. The English in this document has been checked by at least two professional editors, both native speakers of English. For a certificate, please see: http:// www.textcheck.com/certificate/EIYCIL.

\section{Authors' contributions}

J-KK data collection, analysis and writing up, YRS data analysis and statistical advisory, MGK data analysis and statistical advisory, HJK study design determination, SGK research initiative and study design determination. All authors read and approved the final manuscript.

Received: 27 August 2013 Accepted: 30 October 2013

Published: 6 November 2013

\section{References}

1. Rubin MF, Rosas SE, Chirinos JA, Townsend RR: Surrogate markers of cardiovascular disease in CKD: what's under the hood? Am J Kidney Dis 2011, 57:488-497.

2. Simon A, Megnien JL, Chironi G: The value of carotid intima-media thickness for predicting cardiovascular risk. Arterioscler Thromb Vasc Biol 2010, 30:182-185.

3. Kato A, Takita T, Maruyama Y, Kumagai H, Hishida A: Impact of carotid atherosclerosis on long-term mortality in chronic hemodialysis patients. Kidney Int 2003, 64:1472-1479.

4. Benedetto FA, Mallamaci F, Tripepi G, Zoccali C: Prognostic value of ultrasonographic measurement of carotid intima media thickness in dialysis patients. J Am Soc Nephrol 2001, 12:2458-2464.

5. Fernandes VR, Polak JF, Edvardsen T, Carvalho B, Gomes A, Bluemke DA, Nasir K, O'Leary DH, Lima JA: Subclinical atherosclerosis and incipient regional myocardial dysfunction in asymptomatic individuals: the MultiEthnic Study of Atherosclerosis (MESA). J Am Coll Cardiol 2006, 47:2420-2428.

6. Touboul PJ, Hennerici MG, Meairs S, Adams H, Amarenco P, Bornstein N, Csiba L, Desvarieux M, Ebrahim S, Fatar M, Hernandez Hernandez R, Jaff M, Kownator S, Prati P, Rundek T, Sitzer M, Schminke U, Tardif JC, Taylor A, Vicaut E, Woo KS, Zannad F, Zureik M: Mannheim carotid intima-media thickness consensus (2004-2006). An update on behalf of the Advisory Board of the 3rd and 4th Watching the Risk Symposium, 13th and 15th European Stroke Conferences, Mannheim, Germany, 2004, and Brussels, Belgium, 2006. Cerebrovasc Dis 2007, 23:75-80.

7. Nagai Y, Metter EJ, Earley CJ, Kemper MK, Becker LC, Lakatta EG, Fleq JL: Increased carotid artery intimal-medial thickness in asymptomatic older subjects with exercise-induced myocardial ischemia. Circulation 1998, 98:1504-1509.

8. Parrinello G, Colomba D, Bologna P, Licata A, Pinto A, Paterna S, Scaqlione R, Licata G: Early carotid atherosclerosis and cardiac diastolic abnormalities in hypertensive subjects. J Hum Hypertens 2004, 18:201-205.

9. Pauletto P, Palatini P, da Ros S, Pagliara V, Santipolo N, Baccillieri S, Casliqlia E, Mormino P, Pessna AC: Factors underlying the increase in carotid intimamedia thickness in borderline hypertensives. Arterioscler Thromb Vasc Biol 1999, 19:1231-1237.

10. Komorovsky R, Desideri A: Carotid ultrasound assessment of patients with coronary artery disease: a useful index for risk stratification. Vasc Health Risk Manag 2005, 1:131-136.

11. Finn AV, Kolodgie FD, Virmani R: Correlation between carotid intimal/ medial thickness and atherosclerosis: a point of view from pathology. Arterioscler Thromb Vasc Biol 2010, 30:177-181.

12. Spence JD: Technology Insight: ultrasound measurement of carotid plaque-patient management, genetic research, and therapy evaluation. Nat Clin Pract Neurol 2006, 2:611-619.

13. Okin PM, Devereux RB, Jern S, Kjeldsen SE, Julius S, Nieminen MS, Snapinn S, Harris KE, Aurup P, Edelman JM, Wedel H, Lindholm LH, Dahlof B: Regression of electrocardiographic left ventricular hypertrophy during antihypertensive treatment and the prediction of major cardiovascular events. JAMA 2004, 292:2343-2349.

14. Fagard RH, Staessen JA, Thijs L, Celis H, Birkenhager WH, Bulpitt CJ, de Leeuw PW, Leonetti G, Sarti C, Tuomilehto J, Webster J, Yodfat Y: Prognostic significance of electrocardiographic voltages and their serial changes in elderly with systolic hypertension. Hypertension 2004, 44:459-464.

15. Devereux RB, Wachtell K, Gerdts E, Boman K, Nieminen MS, Papademetriou V, Rokkedal J, Harris K, Aurup P, Dahlof B: Prognostic significance of left ventricular mass change during treatment of hypertension. JAMA 2004, 292:2350-2356.

16. Zanchetti A, Hennig M, Hollweck R, Baurecht H, Bond G, Tang R, Cuspidi C, Parati G, Facchetti R, Mancia G: Baseline values but not treatment induced changes in carotid intima media thickness predict incident cardiovascular events in treated hypertensives. Findings in the ELSA. Circulation 2009, 120:1084-1090.

17. Inaba Y, Chen JA, Bergmann SR: Carotid plaque, compared with carotid intima-media thickness, more accurately predicts coronary artery disease events: a meta-analysis. Atherosclerosis 2012, 220:128-133.

18. Baigent C, Landray MJ, Reith C, Emberson J, Wheeler DC, Tomson C, Wanner C, Krane V, Cass A, Craig J, Neal B, Jiang L, Hooi LS, Levin A, Agodoa L, Gaziano M, Kasiske B, Walker R, Massy ZA, Feldt-Rasmussen B, Krairittichai U, Ophascharoensuk V, Fellström B, Holdaas H, Tesar V, Wiecek A, Grobbee D, de Zeeuw D, 
Grönhagen-Riska C, Dasgupta T, SHARP Investigators: The effects of lowering LDL cholesterol with simvastatin plus ezetimibe in patients with chronic kidney disease (Study of Heart and Renal Protection): a randomized placebo-controlled trial. Lancet 2011, 377:2181-2192.

19. Wanner C, Krane V, März W, Olschewski M, Mann JF, Ruf G, Ritz E, Ritz E, German Diabetes and Dialysis Study Investigators: Atorvastatin in patients with type 2 diabetes mellitus undergoing hemodialysis. N Eng J Med 2005, 353:238-248.

20. Fellström BC, Jardine AG, Schmieder RE, Holdaas H, Bannister K, Beutler J, Chae DW, Chevaile A, Cobbe SM, Grönhagen-Riska C, de Lima JJ, Lins R, Mayer G, McMahon AW, Parving HH, Remuzzi G, Samuelsson O, Sonkodi S, Sci D, Süleymanlar G, Tsakiris D, Tesar V, Todorov V, Wiecek A, Wüthrich RP, Gottlow M, Johnsson E, Zannad F, AURORA Study Group: Rosuvastatin and cardiovascular events in patients undergoing hemodialysis. N Engl J Med 2009, 360:1395-1407.

21. Zaslavsky LM, Pinotti AF, Gross JL: Diastolic dysfunction and mortality in diabetic patients on hemodialysis: a 4.25-year controlled prospective study. J Diabetes Complications 2005, 19:194-200.

22. Wang AY, Sanderson JE: Current perspectives on diagnosis of heart failure in long-term dialysis patients. Am J Kidney Dis 2011, 57:308-319.

23. Kim SJ, Han SH, Park JT, Kim JK, Oh HJ, Yoo DE, Yoo TH, Kang SW, Choi KH: Left atrial volume is an independent predictor of mortality in CAPD patients. Nephrol Dial Transplant 2011, 26:3732-3739.

24. Wang AY, Wang M, Lam CW, Chan IH, Zhang Y, Sanderson JE: Left ventricular filling pressure by Doppler echocardiography in patients with end-stage renal disease. Hypertension 2008, 52:107-114.

25. Harma R, Pellerin D, Gaze DC, Mehta RL, Gregson H, Streather CP, Collinson PO, Brecker SJ: Mitral peak Doppler E-wave to peak mitral annulus velocity ratio is an accurate estimate of left ventricular filling pressure and predicts mortality in end-stage renal disease. J Am SoC Echocardiogra 2006, 19:266-273.

26. Munakata M, Sakuraba J, Tayama J, Furuta T, Yusa A, Nunokawa T, Yoshinaga K, Toyota T: Higher brachial-ankle pulse wave velocity is associated with more advanced carotid atherosclerosis in end-stage renal disease. Hypertens Res 2005, 28:9-14.

27. Yambe M, Tomiyama H, Hirayama Y, Gulniza Z, Takata Y, Koji Y, Motobe K, Yamashina A: Arterial stiffening as a possible risk factor for both atherosclerosis and diastolic heart failure. Hypertens Res 2004, 27:625-631.

28. Recio-Mayoral A, Banerjee D, Streather C, Kaski JC: Endothelial dysfunction, inflammation and atherosclerosis in chronic kidney disease-a cross-sectional study of predialysis, dialysis and kidney-transplantation patients. Atherosclerosis 2011, 216:446-451.

29. Lee JK, Lin HH, Tsai CT, Chen JJ, Kuo CC, Lien YC, Lin JW, Huang JW, Hwang SW, Hwang JJ, Tseng CD, Chiang FT, Chen JJ, Wu CK: Differential association of proinflammatory cytokines with left ventricular diastolic dysfunction in subjects with and without continuous ambulatory peritoneal dialysis. Nutr Metab Cardiovasc Dis 2012, 22:974-980.

30. Prabhu SD: Cytokine-induced modulation of cardiac function. Circ Res 2004, 95:1140-1153.

doi:10.1186/1471-2261-13-96

Cite this article as: Kim et al:: Clinical significance of subclinical carotid atherosclerosis and its relationship with echocardiographic parameters in non-diabetic chronic kidney disease patients. BMC Cardiovascular Disorders 2013 13:96.

\section{Submit your next manuscript to BioMed Central and take full advantage of:}

- Convenient online submission

- Thorough peer review

- No space constraints or color figure charges

- Immediate publication on acceptance

- Inclusion in PubMed, CAS, Scopus and Google Scholar

- Research which is freely available for redistribution 